\title{
Introduction
}

\author{
Special Issue on
}

Medicalization and Masculinities

\author{
by Karen Hvidtfeldt, Camilla Bruun Eriksen, Michael \\ Nebeling Petersen \& Kristian Møller
}

How are the bodily interventions of medicalization taking shape in contemporary society? What are the gendered effects of medicalization, and in what ways are contemporary masculinities being transformed culturally and bodily? Are contemporary gay and/or trans masculinities medicalized in new ways? And what are the experiences of, and possibilities found within, (new) masculinities?

These are some of the questions that have inspired this special issue of Women, Gender \& Research on Medicalization and Masculinities. Different gendered bodies have traditionally been the subject of medical interventions and beauty-enhancing treatments of an intimate kind. Within gender studies, the focus has mainly been on female bodies in the reproductive age, concerning various rejuvenation and beauty regimes and following the technological developments of, for instance, fertility technologies and reproductive biomedicine. However, in a Western context, cosmetic surgery is no longer reserved for feminized, privileged, or subcultural groups but is increasingly understood as an acceptable tool to 'fix', e.g., signs of aging or 'overweight' and thus also to achieve a 'normal' (masculinized) body (Atkinson, 2008). The male body has even, according to Jamie Hakim (2019), become sexualized in the same ways as the female body has been, as a means to achieve value within a neoliberalism in which both male and female bodies are increasingly precarious.

Within masculinity studies, a body of scholarly literature is currently emerging, investigating new phenomena in the intersection between masculinities and medicalization, e.g., 'andropause' and 'sexual fitness' (e.g., Rosenfeld and Faircloth 2006; Featherstone \& Hepworth; 1985a, 1985b; Gullette 1997, 1998; Marshall 2007; Marshall \& Katz 2002). Importantly, some masculinities have historically been the object of medicalization and medical intervention: Boys have been diagnosed and regulated through systems of pathologization (e.g., Timimi 2011; Hart, Grand \& Riley 2006) while indigenous, racialized, sexually minoritized and gendered minoritized, as well as disabled men, are medicalized in different and often cruel and inhuman ways within different systems of oppression, 
e.g., colonialism, settler-colonialism, Nazism, white supremacist and cis-heterosexist systems, etc. Within patriarchal and white supremacist societies, however, the white cis-heterosexual adult man has generally avoided medical attention and interventions until ageing beyond midlife, which typically marked the point at which white male bodies could be safely folded into a medicalized regime without necessarily having their masculinity threatened. Cultural shifts have (at least partly) changed this and today both younger white male bodies and middle-aged white male bodies are perceived as in need of regulation/discipline and are therefore increasingly subjected to treatments and modifications, e.g., rejuvenating products and treatments, medicine and other substances enhancing vitality and sexual desire, and aligning bodies to aged, gendered, and sexualized norms of beauty (Bordo 2000; Rosenfeld \& Faircloth 2006; Conrad 2007; Kampf, Marshall, \& Petersen 2013). Trans bodies - at least in Denmark and unlike intersexed bodies (Holm \& Bülow 2020) are pathologized to a lesser extent but are rather being included in health regimes and thereby into other forms of medicalization (e.g., in 2018, the clinical practice guidelines from the World Health Organization (WHO) removed 'transsexuality' from being considered a pathological condition). Such inclusions often challenge gendered norms of embodiment, e.g., within fertility treatments, and therefore research on such issues also questions traditional assumptions within masculinity and gender studies.

This special issue is a collection of articles that investigates the medicalization of bodies from different vantage points, disciplines, and theoretical and empirical settings. The articles aim to challenge and expand the binary categorizations and assessments (healthy vs. ill, necessary vs. un-necessary, artificial vs. natural, body vs. culture, etc.) through critical investigations. More specifically, we are interested in the investigation of what is perceived as male bodies and the intimate issues of medicalization in relation to masculinities. Within critical masculinity studies, masculinities are often viewed as negotiated positions deriving from a variety of practices and positions established in relation to each other, rather than as solely stemming from, and pertaining to, the male-sexed body (e.g., Hearn 2004; Connell \& Messerschmidt 2005; Kimmel 2005; Race 2009). Thus, the concept of masculinity is a dynamic and multifaceted phenomenon emerging from cultural, material, and discursive frames and contexts. We are especially interested in understanding how medicalization can be theorized and analyzed as a complex phenomenon; both a biotechnological and a cultural development that does not unequivocally disturb the body, but rather modifies it. This resembles the bodily extension of prostheses in a somatechnical or feminist posthumanist perspective, where bodies and technologies do not exist outside of, or separate from, one another; as Nikki Sullivan and Samantha Murray state: Bodily-being "(...) is always already technologized, and technologies are always already enfleshed" $(2009,7)$.

\section{The issue's contributions}

In the first article, Michael Nebeling Petersen and Karen Hvidtfeldt bring up recent developments within critical masculinity theory in order to understand how masculinities can be and have been conceptualized as a development from 'hegemonic masculinity' to, for instance, 'inclusive masculinity' and 'involved fatherhood.' In the context of recent mainstream critiques of what are termed 'toxic' masculinities (e.g., the normalization of sexual assaults and sexism as shown by the \#MeToo movement), the authors analyze two short films by the international shaving company Gillette: "We believe," published in January 2019 and the so-called 'trans commercial,' "First Shave, the story of Samson," published in May 2019, in order to asses and critically discuss the theories of masculinities and consider to what extent the films place themselves in relation to new/old notions of masculinities.

Secondly, and starting from the question of how to make sense of a war veteran's personal health biography, Sebastian Mohr in his contribution proposes the 'performative effects of diagnosis' as an analytical tool to explore the 
transformations in people's intimate lives that being diagnosed brings with it. Extrapolating from feminist theory, trans studies, STS, and medical anthropology and sociology, he argues that the performative effects of diagnosis allow scholars to explore transformations in people's intimate lives without a foreclosure about the normative dimensions of these transformations. Mohr argues that, rather than only asking how biopolitical and cis and heteronormative normalcy constitutes itself, the performative effects of diagnosis offer the opportunity to explore how these dimensions are (re)configured and (un)done in and through medicalized intimacies.

The issue's third contribution, by Anne Sofie Bach, starts off by taking us back to the 1950s, when legal gender reassignment in Denmark required castration. In 2014, this requirement was abolished, making Denmark the first country in the world to grant access to legal gender reassignment based on a self-definition model to people above the age of 18 . Drawing on the concept of sociotechnical imaginaries and focusing on the concept of reproductive citizenship, Bach brings attention to both the de-medicalization and re-medicalization of transgender bodies and their fertility following this shift in legislation. Additionally, and through notions of coherence between bodies, gender, and parenthood, Bach extends her discussion of reproductive practices of trans men to include a critical discussion of fertility preservation access and surrogacy.

A fourth article, which doesn't relate to this issue's framework of Medicalization and Masculinities, is nonetheless related to ideas about masculine and feminine work places and gendered divisions of labour: "An increased male presence supposedly promotes gender equality [within kindergartens], as men are thought better suited to meet the gender-specific needs of the young boys." Drawing on the results of a questionnaire completed by more than 700 staff members in all of the 80 kindergartens in two Danish municipalities, this assumption is discussed and questioned by the authors Eli Smeplass and Bent Olsen.

Last but certainly not least, this special issue features an interview with the co-editor of the Somatechnics Journal, Professor Sheila L. Cavanagh, on what we are calling "The Psychic life of Gender." In conversation with Michael Nebeling Petersen and Camilla Bruun Eriksen, Cavanagh, among other things, elaborates on being a 'polyamorous thinker' and shares her academic hope that the field of somatechnics and contemporary queer theorists will engage more seriously and consistently with critical psychoanalysis in the future. Psychoanalysis, she argues, has potential when it comes to understanding gender as a complex and affectively loaded force:

From an academic perspective, psychoanalysis can help us understand gender as a symptom. If masculinity and femininity are symptoms, what can they teach us? It is not enough to catalogue what counts, culturally and historically, as masculine and as feminine, but to better understand our passionate attachments to gender - whatever those genders might be. Gender needs to be taken seriously, like a symptom it needs to be respected and interpreted with a critical psychoanalytic attunement to what it inscribes about the history of the subject.

Thus, Cavanagh articulates one of the major ambitions with this special issue, namely, to inspire new theoretically-informed ways of questioning what counts as 'normal,' and to attend to those elements of subjectivity relating to gender, race, and sexuality that are not conscious or self-evident and that complicate the analytical crossroads between medicalization, masculinity, and gender studies. 


\section{References}

Atkinson, M. (2008). Exploring Male Femininity in the 'Crisis': Men and Cosmetic Surgery. Body \& Society, 14(1), pp. 67-87. DOI: 10.1177/1357034X07087531

Bordo, S. (2000). The male body: a new look at men in public and in private. New York: Farrar, Straus and Giroux.

Connell, R. W., \& Messerschmidt, J. W. (2005). Hegemonic Masculinity: Rethinking the Concept. Gender and society, 19(6), pp. 829-859. DOI: 10.1177/0891243205278639

Conrad, P. (2007). The medicalization of society: on the transformation of human conditions into treatable disorders. Baltimore: Johns Hopkins University Press.

Featherstone, M., \& Hepworth, M. (1985a). The history of the male menopause 1848-1936. Maturitas, 7(3), pp. 249-257. DOI: 10.1016/0378-5122(85)90047-7

Featherstone, M., \& Hepworth, M. (1985b). The male menopause: lifestyle and sexuality. Maturitas, 7(3), pp. 235-246. DOI: 10.1016/0378-5122(85)90045-3

Gullette, M. M. (1997). Declining to Decline: Cultural Combat and the Politics of the Midlife. Charlottesville: University of Virginia Press.

Gullette, M. M. (1998). Midlife Discourses in the Twentieth-Century United States: An Essay on the Sexuality, Ideology, and Politics of 'Middle Ageism'. In R. A. Shweder (Ed.), Welcome to Middle Age! (And Other Cultural Fictions), pp. 3-44. Chicago: University of Chicago Press.

Hakim, J. (2019). Work That Body: Male Bodies in Digital Culture. Racial cultural studies. Lanham: Rowman \& Littlefield International.

Hart, N., Grand, N., \& Riley, K. (2006). "Making the Grade: The Gender Gap, ADHD, and the Medicalization of Boyhood". In Rosenfeld D. \& Faircloth C. (Eds.), Medicalized Masculinities, pp. 132-164. Temple University Press.

Hearn, J. (2004). From Hegemonic Masculinity to the Hegemony of Men. Feminist Theory, 5(1), pp. 49-72. DOI: $10.1177 / 1464700104040813$

Holm, M-L \& Bülow, M.H. (2020). "Samtykke for hvem? Medicinske tilgange til interkønnede personer". In: Di Nucci, E., Knox, J.L. \& Jensen, R.T. (red.). 8 cases i medicinsk etik. København: Munksgaard, 75-99.

Kampf, A., Marshall, B. L., \& Petersen, A. R. (2013). Aging men, masculinities and modern medicine. Milton Park, Abingdon, Oxon; New York, NY: Routledge.

Kimmel, M. S. (2005). The history of men: essays in the history of American and British masculinities. Albany: State University of New York Press.

Marshall, B. L. (2007). Climacteric Redux? (Re)medicalizing the Male Menopause. Men and Masculinities, 9(4), pp. 509-529. DOI: 10.1177/1097184X05284224

Marshall, B. L., \& Katz, S. (2002). Forever Functional: Sexual Fitness and the Ageing Male Body. Body \& Society, 8(4), pp. 43-70. DOI: 10.1177/1357034X02008004003

Race, K. (2009). Pleasure consuming medicine: the queer politics of drugs. Durham NC: Duke University Press.

Rosenfeld, D., \& Faircloth, C. A. (2006). Medicalized masculinities. Philadelphia: Temple University Press.

Sullivan, N., \& Murray, S. (2009). Somatechnics: queering the technologisation of bodies. Farnham, Surrey/ Burlington, VT: Ashgate.

Timimi, S. (2011). "Medicalizing masculinity”. In Rapley M., Moncrieff J., Dillon J. (Eds.) De-Medicalizing Misery, pp. 86-98. Palgrave Macmillan, London. 